Part of Journal of Research of the National Bureau of Standards, Volume 17, September 1936

\title{
STRUCTURAL CHARACTERISTICS OF SOME CONSTITUENTS OF PORTLAND CEMENT CLINKER
}

\author{
By Herbert Insley
}

ABSTRACT

Preliminary observations on the constituents of portland cement clinker by the petrographic and metallographic microscopes are recorded. The lack of purity of $3 \mathrm{CaO} . \mathrm{SiO}_{2}$ in some commercial clinker is demonstrated. The structures of $2 \mathrm{CaO} . \mathrm{SiO}_{2}$ in commercial clinker and laboratory preparations are illustrated, and it is suggested that differences in optical properties of specimens of dicalcium silicate may be due to twinning and not to the existence of the alpha modification at room temperatures. It has been shown that glass may be present in at least one type of cement clinker.

\section{CONTENTS}

I. Introduction

II. Metallographic method

1. Procedure

2. Advantages and disadvantages

III. Properties of constituents of cement clinker

1. Constituent A

2. Constituent $\mathrm{B}_{\ldots} \ldots \ldots \ldots$

(a) Optical properties

(b) Types..... 358

3. Constituent $\mathrm{C}$

4. Constituent D

5. Accessory constituents

IV. Quantitative measurements

V. Summary _...

\section{INTRODUCTION}

Recently some investigators ${ }^{1}$ have questioned the generally accepted hypotheses that portland cement clinker is almost completely crystallized and that the compounds present are those which would crystallize when the clinker is cooled under approximately equilibrium conditions. This has led not only to a reexamination of clinker constituents by the customary methods but also to a search for improved methods.

The identification of crystalline compounds in cement clinker has been based primarily on a comparison of their optical properties with those of compounds found in phase studies of systems containing the principal oxides of which cement clinker is composed. The first phase study on this subject was that of Rankin and Wright ${ }^{2}$ on the system

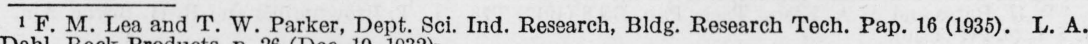
Dahl, Rock Products, p. 26 (Dec. 10, 1932).

2 Am. J. Sci. 39, 1-79 (1915). 
$\mathrm{CaO}-\mathrm{Al}_{2} \mathrm{O}_{3}-\mathrm{SiO}_{2}$. This and later studies ${ }^{3}$ dealing with ternary systems were the basis of Lea and Parker's investigation ${ }^{4}$ of the quaternary system $\mathrm{CaO}-\mathrm{Al}_{2} \mathrm{O}_{3}-\mathrm{Fe}_{2} \mathrm{O}_{3}-\mathrm{SiO}_{2}$. The latter system includes all the essential components of portland cement clinker. Comparative studies on the actual constituents of portland cement clinker ${ }^{5}$ show that three crystalline compounds are found which are closely similar to or identical with three of the compounds found in laboratory studies. These are $3 \mathrm{CaO} . \mathrm{SiO}_{2}, 2 \mathrm{CaO} . \mathrm{SiO}_{2}$, and $4 \mathrm{CaO}$. $\mathrm{Al}_{2} \mathrm{O}_{3} \cdot \mathrm{Fe}_{2} \mathrm{O}_{3}$. The relations of magnesia, an almost universal impurity in clinker, to lime, alumina and silica have been studied by McMurdie and Insley. ${ }^{6}$

The present investigation was, in part, an outgrowth of microscopic studies on clinker used in the manufacture of the so-called "low-heat" 7 portland cement for construction of Boulder Dam. Refinements in technique and applications of microscopic methods hitherto little used for observations on cement indicated that some constituents differed somewhat in composition from the formulas generally assigned to them. This led to a reexamination of both commercial and laboratory clinker in order that information might be obtained on the structure of the constituents, the departures from equilibrium in the cooled clinker, and the deviations from constant composition in the individual compounds. The purpose of this paper is to record the results of these examinations and to describe an extremely useful method of microscopic examination using polished specimens and reflected light.

\section{METALLOGRAPHIC METHOD}

\section{PROCEDURE}

The method of preparation and examination of specimens commonly used by the metallographer, that is, polishing a prepared plane surface on the specimen, etching with a suitable reagent, and examining with reflected light, was applied to portland cement clinker many years ago ${ }^{8}$ but, largely because of poor technique, the method was generally abandoned until its recent revival by Tavasci. ${ }^{9}$

The method of preparation and examination used is essentially as follows. Unless the clinker specimen is very dense it is generally impregnated, before grinding, with a resin ${ }^{10}$ which is unattacked by alcohol. A flat face is then ground on the clinker specimen with coarse silicon carbide and the final grinding is done with fine emery. After careful washing the specimen is polished with a mixture of optical rouge and water on a rotating lap covered with coarse duck. The polishing is continued until the specimen is dry in order to remove any surface film of hydrated material. The specimen is then etched with a suitable reagent. After considerable experimentation a 1-percent solution of nitric acid in ethyl alcohol was found to be the best general etchant for clinker. With this reagent an etching time of somewhat less than 5 seconds is satisfactory. The speci-

\footnotetext{
${ }^{3}$ W. C. Hansen, L. T. Brownmiller, and R. H. Bogue, J. Am. Chem. Soc. 50, 396 (1928). W. C. Hansen and R. H. Bogue, J. Am. Chem. Soc. 48, 1261-1266 (1926).

4 Royal Soc. Phil. Trans. [A] 234, 1-41 (1934).

o P. H. Bates and A. A. Klein, Tech. Pap. BS 8 (1917) T78. L. T. Brownmiller and R. H. Bogue, Am. J. Sci. 20, 241 (1930).

6 J. Research NBS 16, 467 (1936) RP884.

7 These clinkers are characterized by fairly low $\mathrm{CaO}$, high $\mathrm{SiO} \mathrm{O}_{2}$ and a low $\mathrm{Al}_{2} \mathrm{O}_{3} / \mathrm{Fe}_{2} \mathrm{O}_{3}$ ratio (about 1.0).

8 Stein, Mitt. Materialprüfungsamt, Gross-Lichterfelde, 1908, 7. Wetzel, Verein Deut. Portland Cement Fabrik, 1913, 5-72.

Giorn. Chim. Ind. Applicata 16, 538-552 (1934).

10 Hyrax?and? A roclor no. 4465 have been found suitable.
} 


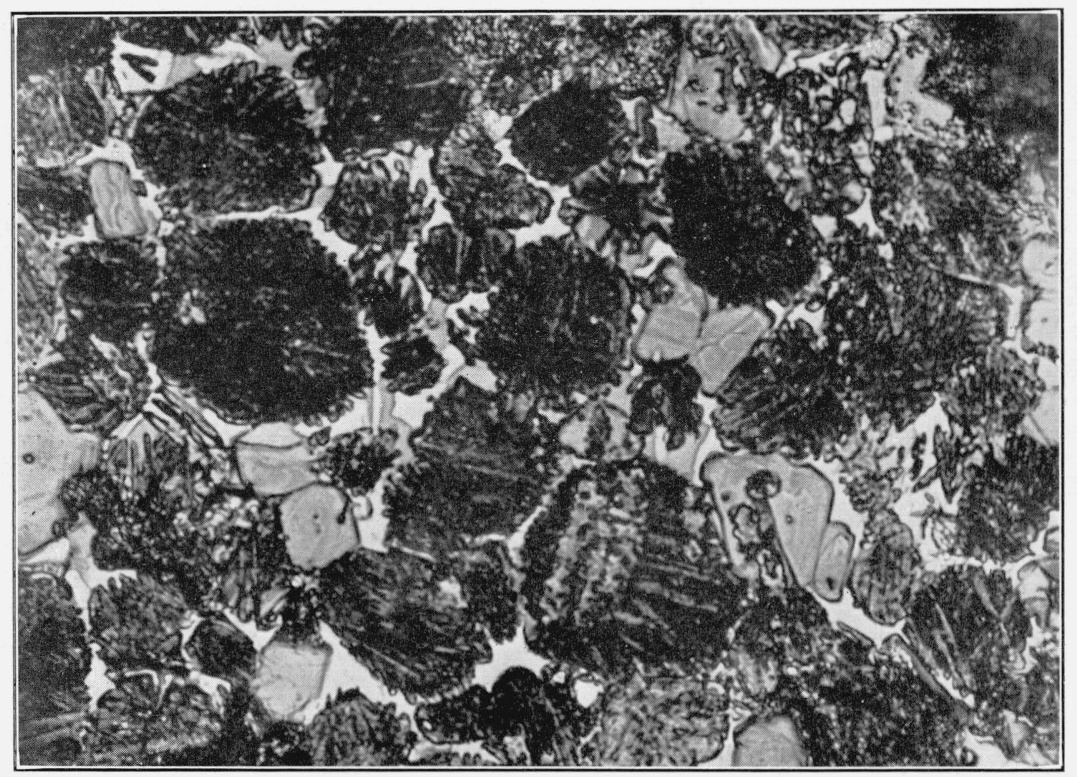

Figure 1.-Low-heat clinker, brand B.

Reflected light. Magnification 500 times.

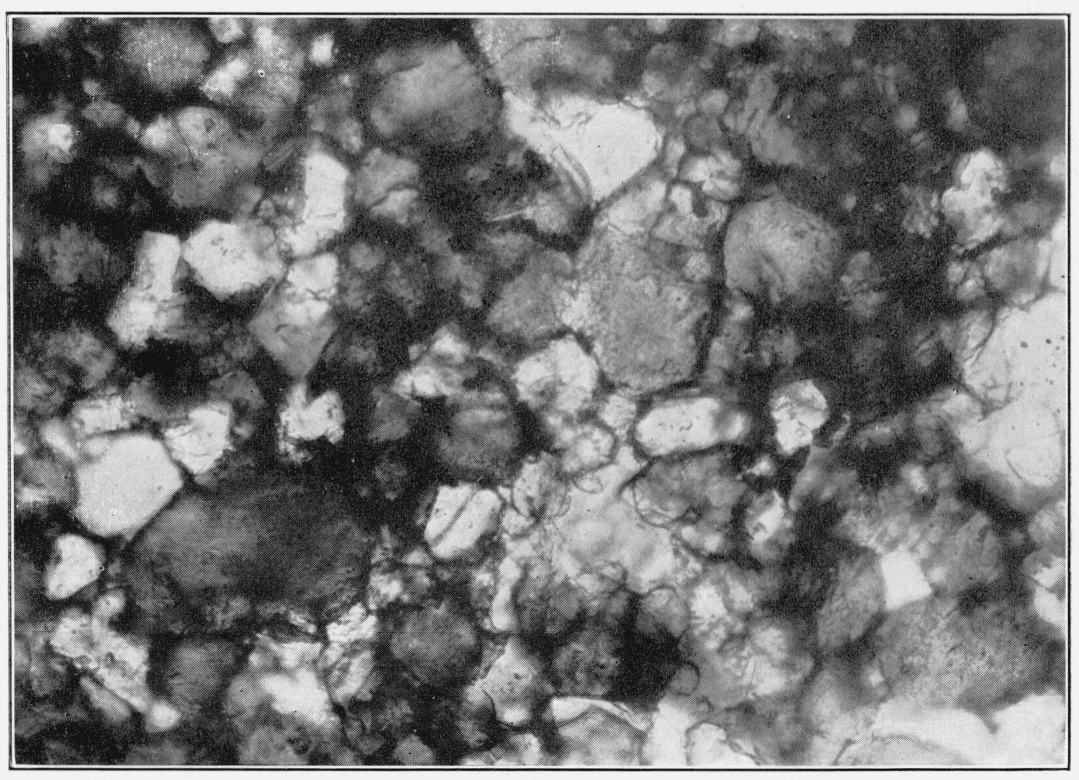

Figure 2.-Low-heat clinker, brand B.

Ordinary transmitted light. Magnification 500 times. 


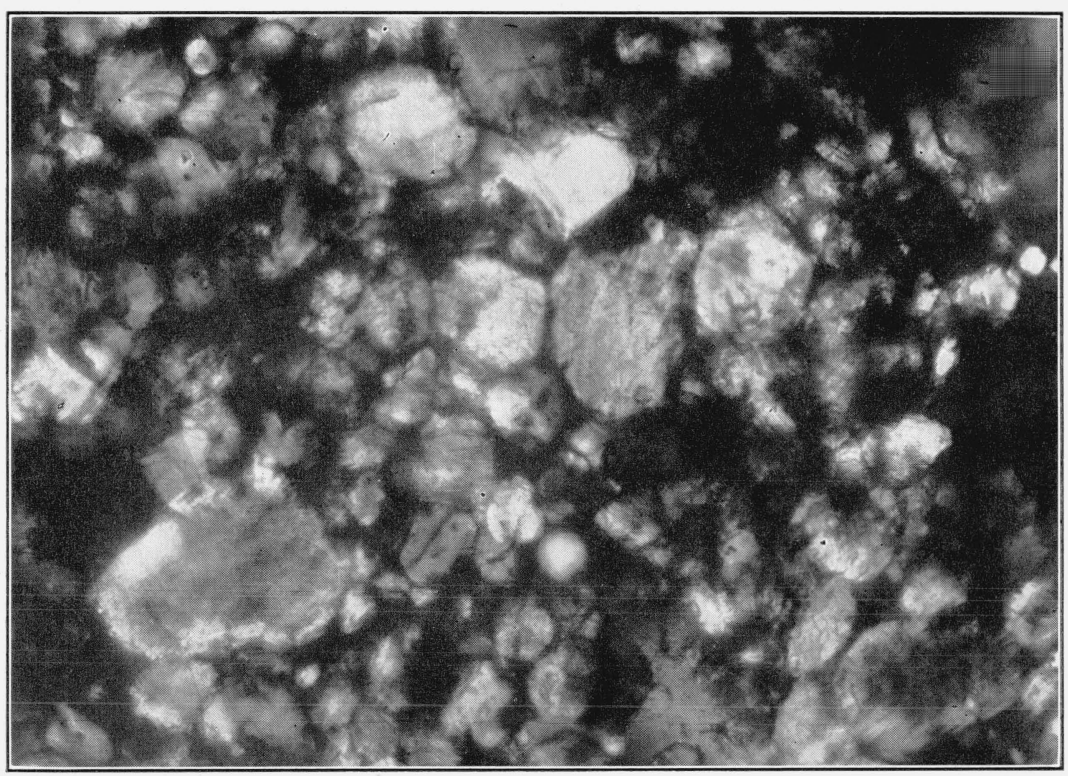

Figure 3.-Low-heat clinker, brand B.

Same field as figure 2, but with crossed nicols. Magnification 500 times. 
mens are examined with a vertical illuminator using a plane glass reflector, yellow-green filter and an attached light source. For photomicrography an arc lamp is substituted for the attached incandescent lamp.

\section{ADVANTAGES AND DISADVANTAGES}

The method of examination of polished sections with reflected light offers several advantages over the method of thin sections with transmitted light. Thin sections are generally 20 to 30 microns thick and, since the average diameter of some of the constituents is considerably less than this range, observation suffers greatly from "overlap" of the constituents within the section. Moreover, the two interstitial constituents are so fine-grained and so closely mixed that they can be distinguished only with the greatest difficulty in thin section. Even in powder preparations viewed in transmitted light it is frequently difficult to distinguish these constituents with certainty. With polished sections, however, the object lies in a single plane and consequently boundaries of individual grains are distinct, and spatial relationships are clear. Therefore, polished sections can be used with much greater precision for quantitative areal measurements.

The contrast in clarity and definition of microscopic images of cement clinker by reflected light and by transmitted light is well illustrated by figures 1, 2, and 3 . These are photomicrographs of the same brand of clinker at the same magnification. Figure 1 shows a polished, etched specimen in reflected light, figure 2 a thin section in transmitted ordinary light, and figure 3 shows the same field as figure 2 with crossed nicols.

The metallographic method has the grave disadvantage that many important optical properties of crystals in the clinker specimens cannot be measured. Primary identifications must be made either by comparison with powder preparations or thin sections on which measurements of indices of refraction, optical character, double refraction, etc., have been made, or by synthesizing the pure compounds and comparing their polished and etched surfaces with those of the cement clinker.

\section{PROPERTIES OF CONSTITUENTS OF CEMENT CLINKER}

By the metallographic method of examination four distinct constituents can be seen in practically all portland cement clinker (fig. 4). For this discussion they are designated A, B, C, and D.

Constituent A occurs usually as relatively large crystals with hexagonal outlines, often exhibiting zonal structure and infrequently showing simple twinning. It is strongly affected by the etching reagent.

Constituent B is present as relatively large, rounded crystals. The crystals are usually striated, sometimes with a single parallel group but more frequently with two intersecting groups of striations. This constituent, like constituent $\mathrm{A}$, is strongly affected by the etching reagent.

Constituent $\mathrm{C}$ is a highly reflecting substance which occurs in the ground mass surrounding grains of constituents A and B. Its crystal form is sometimes difficult to distinguish, because of its habit of ag- 
gregation. The crystals are generally small, often acicular. This constituent is relatively unaffected by the etching reagent.

Constituent $\mathrm{D}$ occurs in the ground mass surrounding crystals of $\mathrm{A}$ and $\mathrm{B}$ and intimately associated with constituent C. It has low reflecting power and is less strongly etched than constituents A and $B$.

\section{CONSTITUENT A}

This constituent occurs abundantly and usually in well-defined crystals with hexagonal outlines in normal portland cement clinker and can be readily distinguished in metallographic specimens (fig. 4). It is easily identified with the hexagonal crystals seen in thin sections and powder preparations. It has weak double refraction, a mean index of refraction of about 1.715, and negative uniaxial (or nearly uniaxial) optical character. First suspected to be tricalcium silicate by Le Chatelier, ${ }^{11}$ it was later identified as that compound by Rankin and Wright. ${ }^{12}$

Petrographic, metallographic, and X-ray examinations of some commercial clinkers indicate solid miscibility in $3 \mathrm{CaO} \cdot \mathrm{SiO}_{2}$, but equilibrium studies on systems in which $3 \mathrm{CaO} . \mathrm{SiO}_{2}$ occurs as a crystalline phase have not furnished substantiating evidence. Figure 5 is a photomicrograph in reflected light of a commercial clinker in which the tricalcium silicate crystals show zones or bands approximately parallel to the external faces of the crystals. Similar zonal structure, clearly seen also in figure 4 , was observed by Tavasci ${ }^{13}$ in some specimens etched with dilute hydrofluoric or nitric acid. $\mathrm{He}$ attributed the phenomenon to etching at too high a temperature or to failure to agitate the specimen in the etching reagent. It is not apparent how such zonal structures could be obtained in homogeneous crystals no matter how the etching reagent is used.

In thin sections of commercial clinker interference figures of tricalcium silicate frequently depart considerably from perfect uniaxiality, while sections of crystals oblique to the optic axis often exhibit a change in extinction angle from interior to exterior of the crystal. ${ }^{14}$ Variations in indices of refraction in specimens of tricalcium silicate obtained from basic open-hearth slags have been reported by Andersen and Lee ${ }^{15}$ and have been ascribed by them to solid solution. Crystals of $3 \mathrm{CaO} . \mathrm{SiO}_{2}$ in portland cement clinker are generally so difficult to free from adhering substances that indices of refraction cannot be determined accurately.

A general shift in position of lines in the X-ray diffraction pattern of a crystalline compound in the presence of impurities as compared with a pattern of the pure compound may indicate solid solution. A small but significant shift in position may be seen in figure 6 where the pattern of a commercial clinker containing a large amount of $3 \mathrm{CaO} . \mathrm{SiO}_{2}$ is compared with that of $3 \mathrm{CaO} . \mathrm{SiO}_{2}$ made from pure $\mathrm{CaO}$ and $\mathrm{SiO}_{2}$. Similar shifts have been observed also on other patterns of commercial clinker as well as one or two laboratory preparations. The nature of the compound taken into solution by the tricalcium silicate has not been determined.

11 Compt. rend. 94, 13 (1882).

12 Am. J. Sci. 39, 1-79 (1915)

13 Giorn. Chim. Ind. A pplic. 16, 539 (1934).

14 The change in extinction angle was pointed out to the author by Dr. L. S. Brown.

$13 \mathrm{~J}$. Wash. Acad. Sci. 23, 338-351 (1933). These authors attribute departures from uniaxiality to the presence of regularly oriented lamellar inclusions in $3 \mathrm{CaO} \cdot \mathrm{SiO}$. However, such inclusions are not commonly observed in portland cement clinker. 


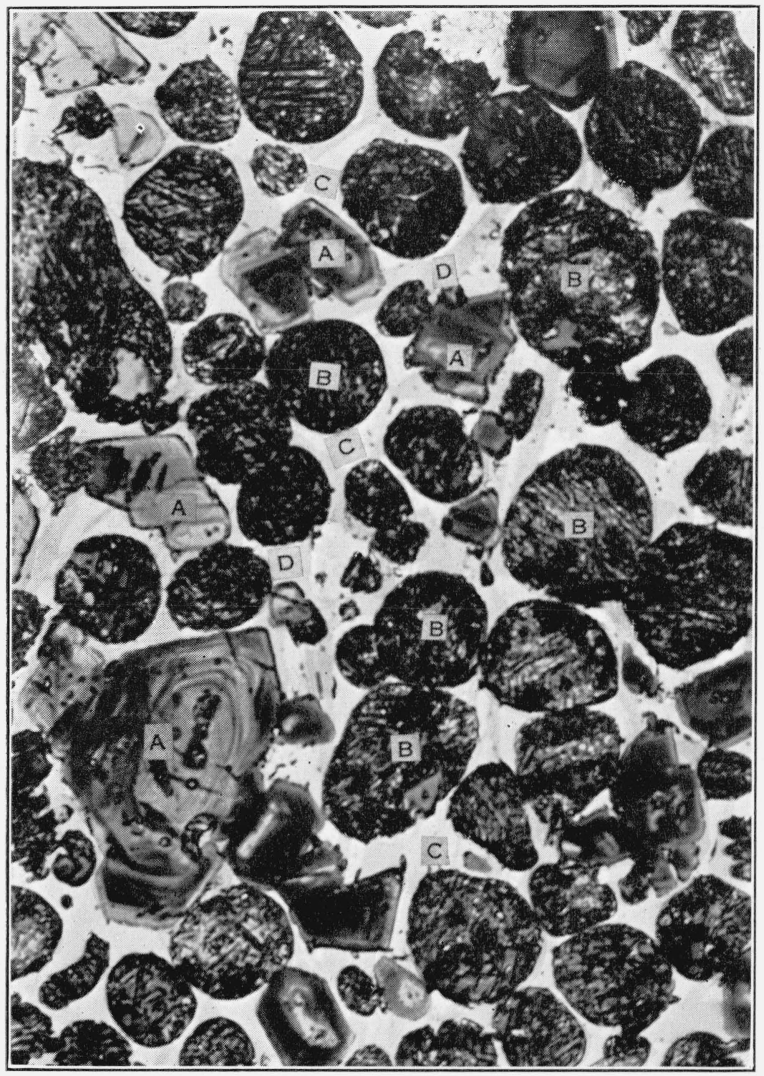

Figure 4.-Low-heat clinker, brand A.

Reflected light. Magnification 500 times. The letter designations on the photomicrograph refer to constituent designations in the text, p. 855 . 


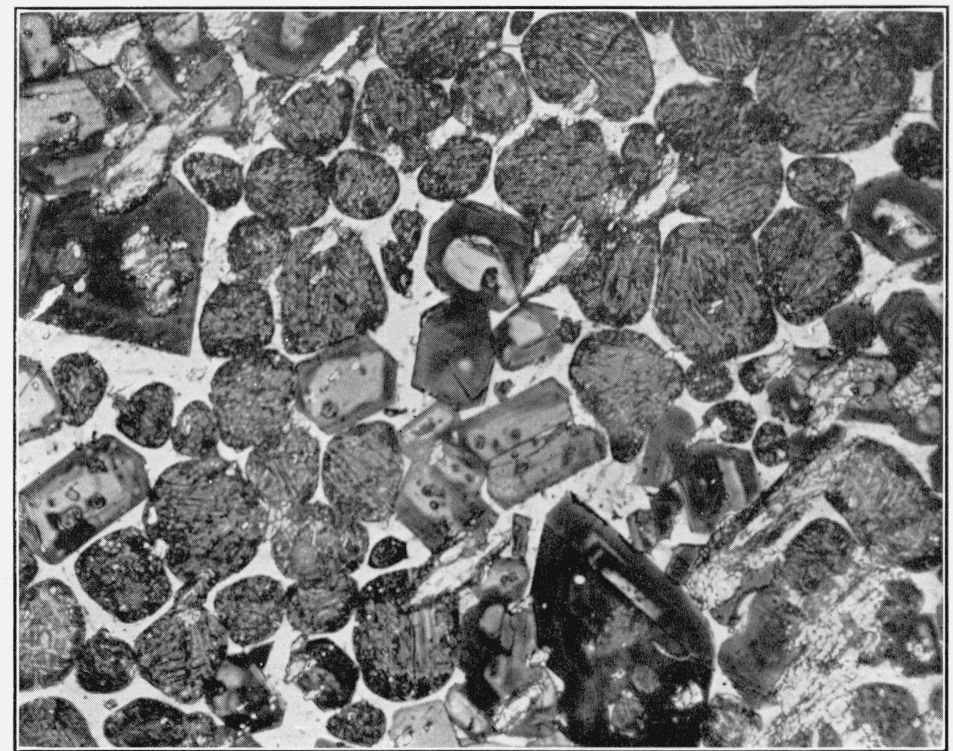

Figure 5.-Low-heat clinker, brand C.

Showing zonal structure in $3 \mathrm{CaO} \cdot \mathrm{SiO}_{2}$. A large $3 \mathrm{CaO} \cdot \mathrm{SiO}_{2}$ crystal having a single twinning plane is seen. Reflected light. Magnification 500 times.

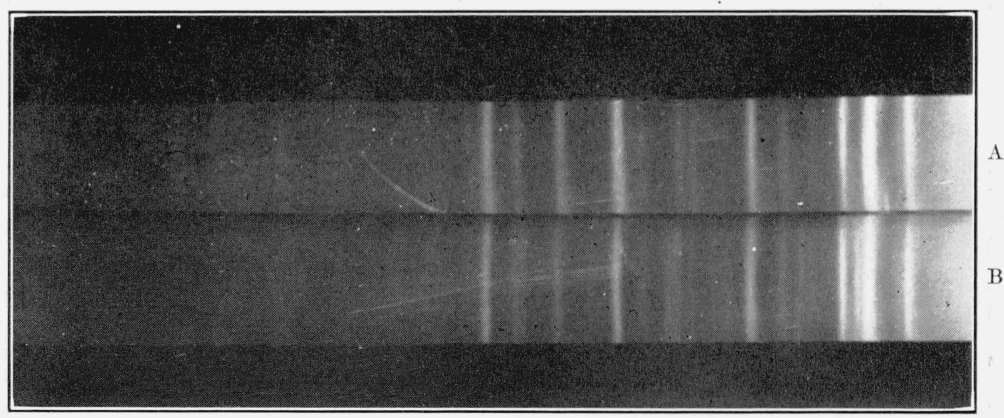

Figure 6.-Powder diffraction pattern of a cement clinker containing a large amount of $3 \mathrm{CaO} . \mathrm{SiO}_{2}$ compared with that of pure $3 \mathrm{CaO} . \mathrm{SiO}_{2}$.

$$
\begin{aligned}
& \text { A.-Pure } 3 \mathrm{CaO} . \mathrm{SiO}_{2} \text {. } \\
& \text { B.-Portland-cement clinker. }
\end{aligned}
$$




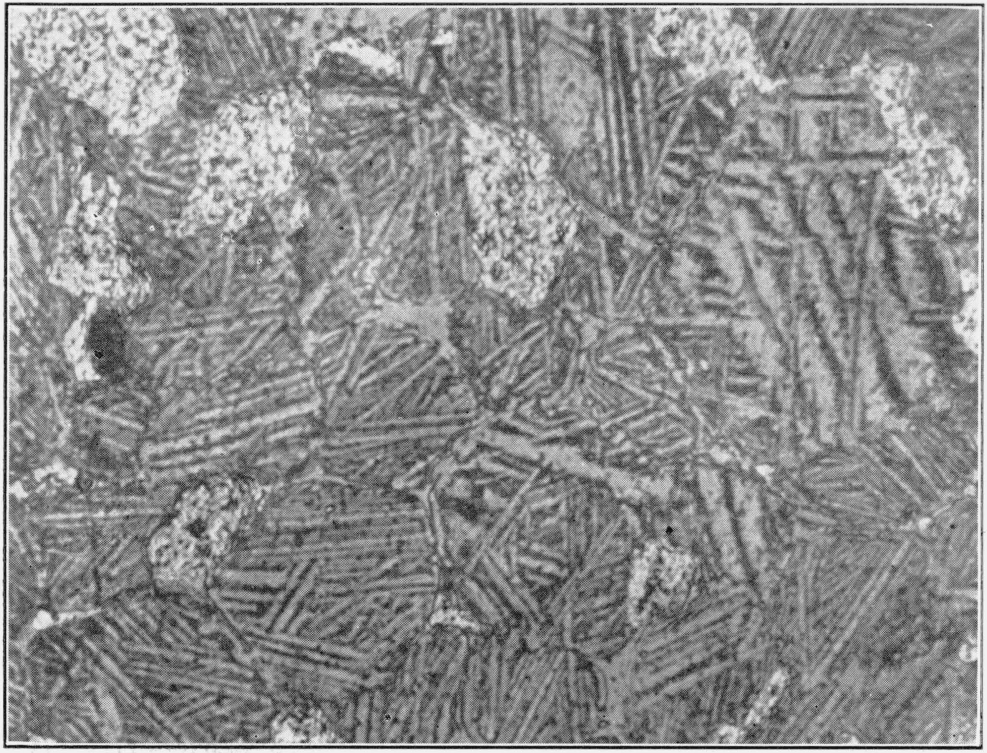

FiguRE 7.-Dicalcium silicate quenched after heating at $1,450^{\circ} \mathrm{C}$. Reflected light. Magnification 509 times.

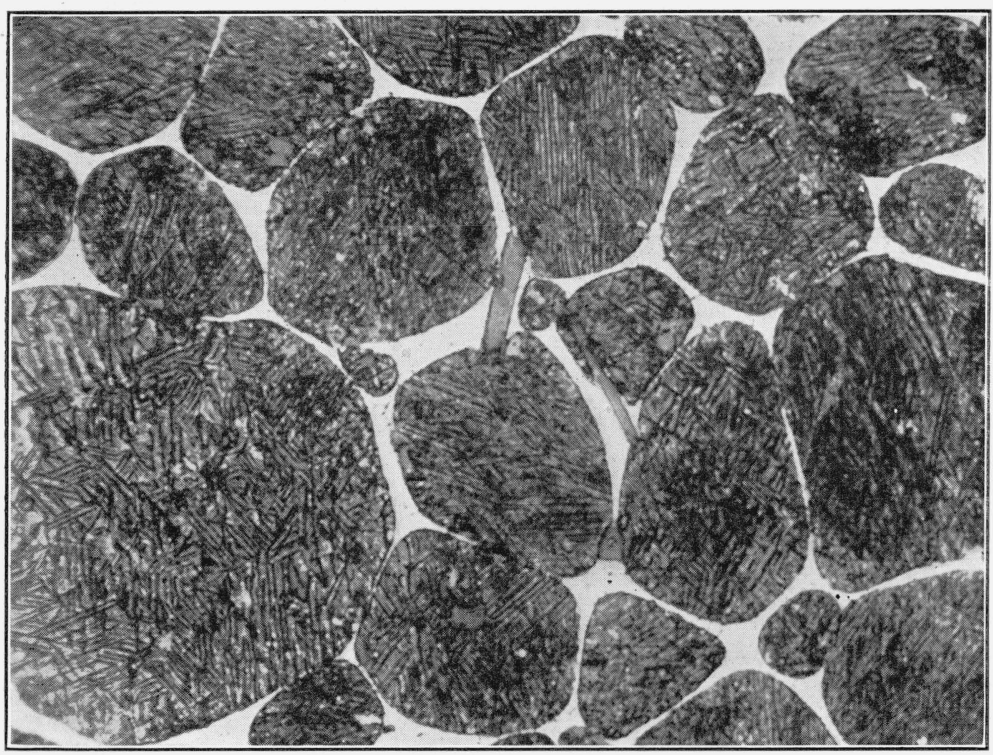

FIgURE 8.-Twinning structure in dicalcium silicate crystals in low-heat clinker, brand $\mathrm{A}$.

Reflected light. Magnification 1,000 times. 


\section{CONSTITUENT B}

\section{(a) OPTICAL PROPERTIES}

The compound $2 \mathrm{CaO} . \mathrm{SiO}_{2}$ has long been known to be one of the principal constituents of portland cement clinker. Three forms have been identified. ${ }^{16}$ Two of them, $\alpha$ and $\beta$, are presumed to be present in sound clinker. The third form, $\gamma 2 \mathrm{CaO} . \mathrm{SiO}_{2}$, is found in significant quantities only in "dusted" clinker and its characteristics will not be discussed here.

Sundius ${ }^{17}$ has measured the optical properties of $\alpha$ and $\beta 2 \mathrm{CaO} . \mathrm{SiO}_{2}$ as they exist in portland cement clinker. He notes that the $\alpha$ form is characterized by two sets of fine polysynthetic twinning bands meeting at a steep angle and that the optic axial angle varies from 30 to $50^{\circ}$ in different crystals. The $\beta$ form differs from the $\alpha$ form slightly in indices of refraction, the optic axial angle is larger $\left(70^{\circ}\right.$ or more) and twinning in samples of the $\beta$ form heated below $1,420^{\circ} \mathrm{C}$ (the $\alpha \rightleftharpoons \beta$ inversion temperature) is characteristically a single set of polysynthetic bands. The indices of refraction of the two forms as given by Rankin and Wright and by Sundius are as follows:

$$
\begin{aligned}
& \text { Rankin and Wright } \\
& \text { Sundius }
\end{aligned}
$$

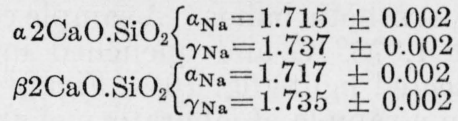

$$
\begin{aligned}
& \begin{array}{l}
a=1.719 \pm 0.001 \\
\gamma=1.733 \pm 0.001 \\
a=1.717 \pm 0.001 \\
\gamma=1.736 \pm 0.001
\end{array}
\end{aligned}
$$

It is significant that the differences in values between the two forms as given by each observer are practically within the limits of precision specified.

It is worthy of note that the complicated twinning found in the so-called " $\alpha$ " form is almost universally present and that, therefore, optical properties very probably are measured on twinned grains. Twinning bands are generally exceedingly narrow, often less than a micron in width (figs. 7 and 8). Since corresponding principal vibration directions are inclined symmetrically in adjacent twinning bands, it is evident that indices of refraction in principal vibration directions measured by the immersion method on such grains may be considerably in error. The apparent optic axial angle and the apparent double refraction also may vary considerably, because of differences in the number and width of twinning bands. The possibility seems to have been overlooked that crystals of $2 \mathrm{CaO}^{-\mathrm{SiO}_{2}}$ as found in clinker as well as in laboratory preparations may all be in the $\beta$ state, and that the complex twinning often cited as indicative of the $\alpha$ state may be in reality only an indication that the crystal has at some time been in the $\alpha$ state. The production of twinning as a result of passing from one polymorphic state to another on cooling is well known. ${ }^{18}$

To substantiate this, samples of $2 \mathrm{CaO} . \mathrm{SiO}_{2}$ were made and mixed with the stabilizing substances used by Sundius $\left(\mathrm{Cr}_{2} \mathrm{O}_{3}, 3 \mathrm{CaO} \cdot \mathrm{Al}_{2} \mathrm{O}_{3}\right.$, and $\left.3 \mathrm{CaO} \cdot \mathrm{SiO}_{2}\right)$. Specimens were mixed also with a small amount (0.2 percent) of $\mathrm{B}_{2} \mathrm{O}_{3}$. These were heated in either a platinumresistance furnace or an oxyhydrogen blowtorch to temperatures well

16 G. A. Rankin and F. E. Wright, Am. J. Sci. 39, 1-79 (1915).

$17 \mathrm{Z}$. anorg. allgem. Chem. 213, 343-352 (1933).

18 H. Le Chatelier, The Constitution of Hydraulic Mortars, p. 53 (McGraw-Hill Book Co., New York, $1905)$. 
above $1,450^{\circ} \mathrm{C}$ and quenched in ice water or mercury. A comparison of their X-ray powder patterns with samples of the same material heated at $1,375^{\circ} \mathrm{C}$ showed complete identity in number, position, and intensity of lines.

\section{(b) TYPES}

Twinning in $2 \mathrm{CaO} . \mathrm{SiO}_{2}$ is exhibited in transmitted polarized light as parallel bands with extinction inclined in opposite directions in adjacent bands. In reflected light the twinning appears as parallel striations. A sample of $2 \mathrm{CaO} . \mathrm{SiO}_{2}$ containing 0.2 percent of $\mathrm{B}_{2} \mathrm{O}_{3}$ after heating at $1,450^{\circ} \mathrm{C}$ and quenching in mercury is shown in figure 7. Individual grains show at least two and sometimes three sets of interpenetrating striations, each set being composed of parallel bands. A mixture of $\mathrm{CaO}, \mathrm{Al}_{2} \mathrm{O}_{3}, \mathrm{Fe}_{2} \mathrm{O}_{3}$, and $\mathrm{SiO}_{2}$ in the proportions characteristic of some "low-heat" clinker, and which had been heated to $1,450^{\circ} \mathrm{C}$ and quenched, showed the same complicated striations in the dicalcium silicate (fig. 9). A polished section of commercial low-heat clinker as received from the manufacturer is shown in figure 8. This type of twinning has generally been considered characteristic of $\alpha 2 \mathrm{CaO} . \mathrm{SiO}_{2}$. It will here be called type I.

Dicalcium silicate heated below $1,420^{\circ} \mathrm{C}$ frequently occurs as grains having a single set of polysynthetic bands. A sample containing 0.2 percent of $\mathrm{B}_{2} \mathrm{O}_{3}$ heated at $1,375^{\circ} \mathrm{C}$ and quenched in mercury shows parallel striations in reflected light (fig. 10). Figure 11 shows this type of banding as found in a sample of laboratory clinker of the same composition as that shown in figure 9 but heated at $1,375^{\circ} \mathrm{C}$ instead of $1,450^{\circ} \mathrm{C}$. We may call this $2 \mathrm{CaO} \cdot \mathrm{SiO}_{2}$ of type II. Commercial clinkers made in rotary kilns rarely contain dicalcium silicate of type II.

Still a third type, which we may designate as type III, is found in commercial as well as synthetic clinker. It appears to be untwinned, but it is frequently found as overgrowths on grains of type I. In commercial clinker type III frequently occurs as irregular grains with what appear to be veinlets or cracks running through them. This is shown clearly in figure 12 , in which $2 \mathrm{CaO} . \mathrm{SiO}_{2}$ of type III occurs both as individual grains and as small rounded inclusions in $3 \mathrm{CaO} \cdot \mathrm{SiO}_{2}$. Figure 13 shows still another clinker in which layers of type III are overgrown on type I. Another photomicrograph of this clinker (fig. 1) shows fingers of $2 \mathrm{CaO}^{-\mathrm{SiO}_{2}}$ extending into the matrix material, apparently a result of crystallization during cooling. In experiment with laboratory preparations the untwinned form was obtained only when moderately slow cooling below the $\alpha \rightleftharpoons \beta$ inversion temperature was permitted before quenching. Figure 14 is a photomicrograph of a sample of laboratory clinker allowed to cool from 1,375 to $1,275^{\circ} \mathrm{C}$ before quenching. Small individual elongated grains of type III and overgrowths of type III on type II are visible. Petrographic examination of these specimens shows the presence of untwinned crystals with moderate double refraction and with indices of refraction approximately those of $\alpha$ or $\beta 2 \mathrm{CaO} . \mathrm{SiO}_{2}$.

In general, these observations confirm those of Tavasci ${ }^{19}$ on the structural characteristics, although no evidence has been obtained in the present work to support his rather broad generalizations concerning the occurrence of solid solution of other substances in $2 \mathrm{CaO} \cdot \mathrm{SiO}_{2}$.

\footnotetext{
10 Giorn. Chim. Ind. Applic. 16, 538-552 (1934).
} 


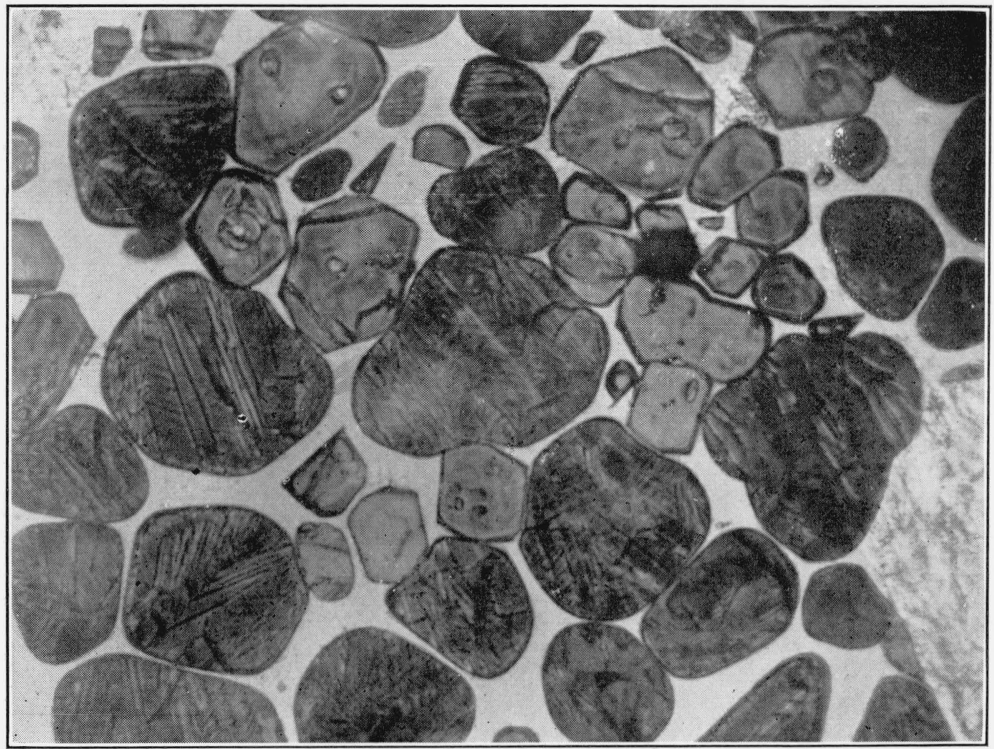

Figure 9.-Laboratory-prepared low-heat clinker, quenched after heating to $1,450^{\circ} \mathrm{C}$. Reflected light. Magnification 500 times.

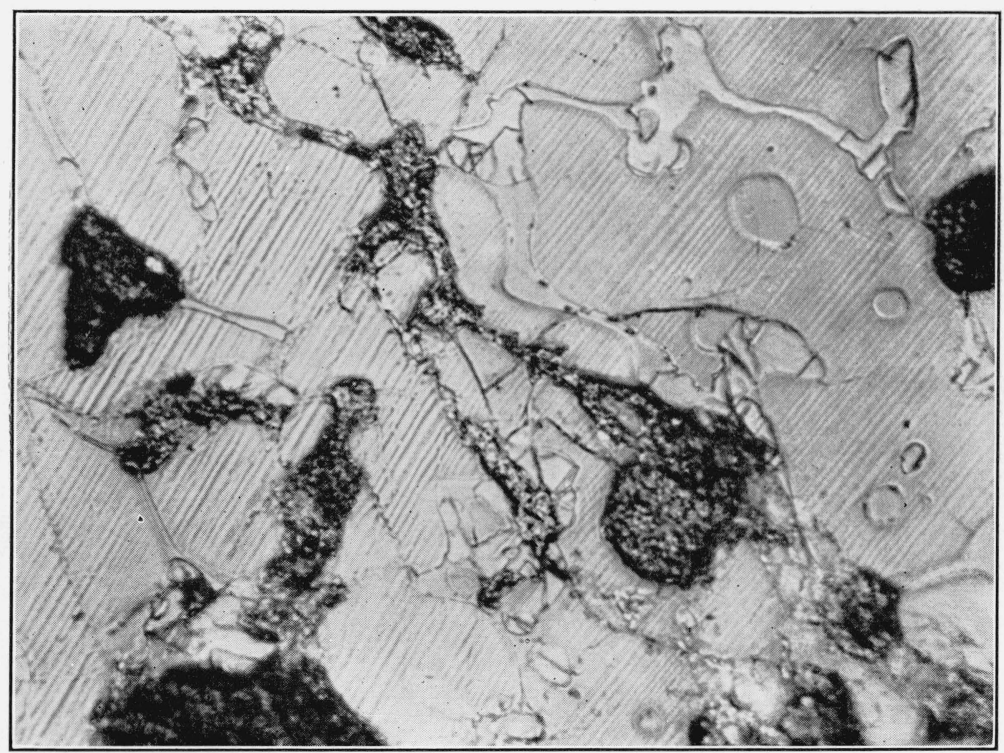

Figure 10.-Dicalcium silicate containing 0.2 percent of $\mathrm{B}_{2} \mathrm{O}_{3}$ quenched after heating to $1,375^{\circ} \mathrm{C}$.

Reflected light. Magnification 1,000 times. 


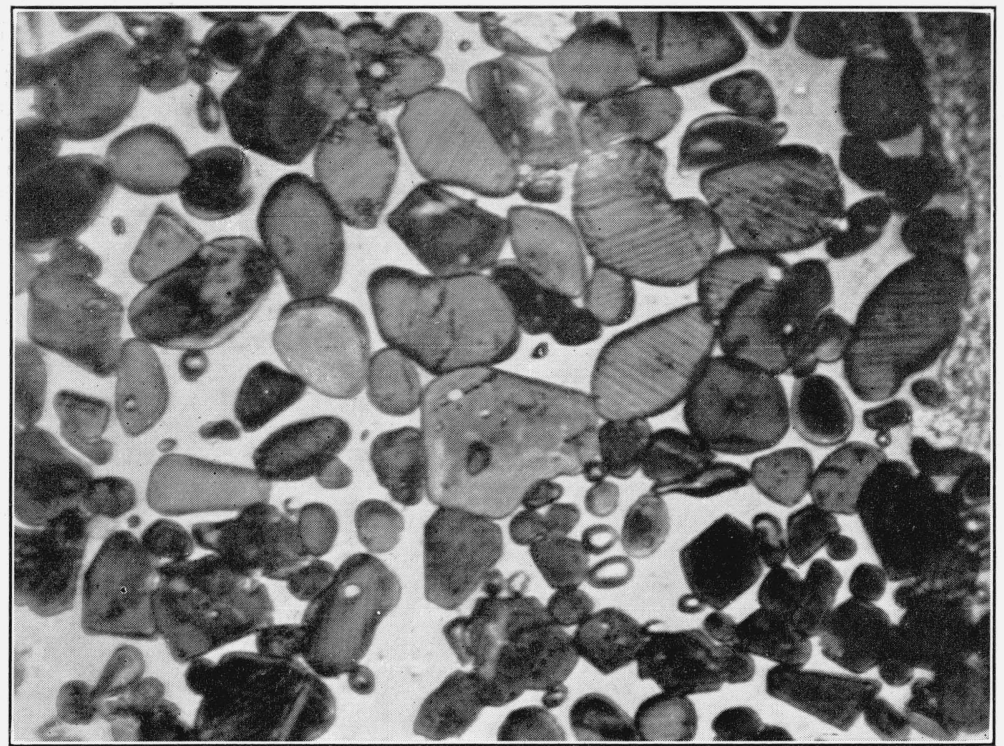

FiguRE 11.-Laboratory-preparedlow-heat clinker quenched after heatıng at $1,375^{\circ} \mathrm{C}$. Reflected light. Magnification 500 times.

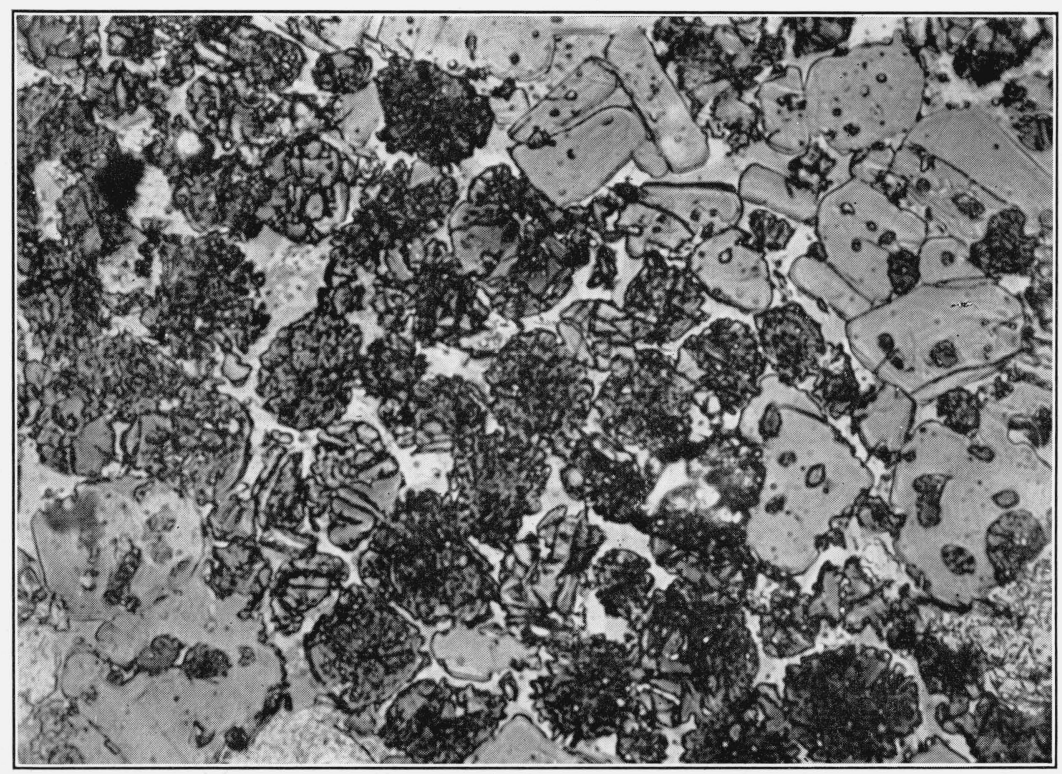

Figure 12.-Dicalcium silicate of type III in low-heat clinker of brand D. Reflected light. Magnification 500 times. 


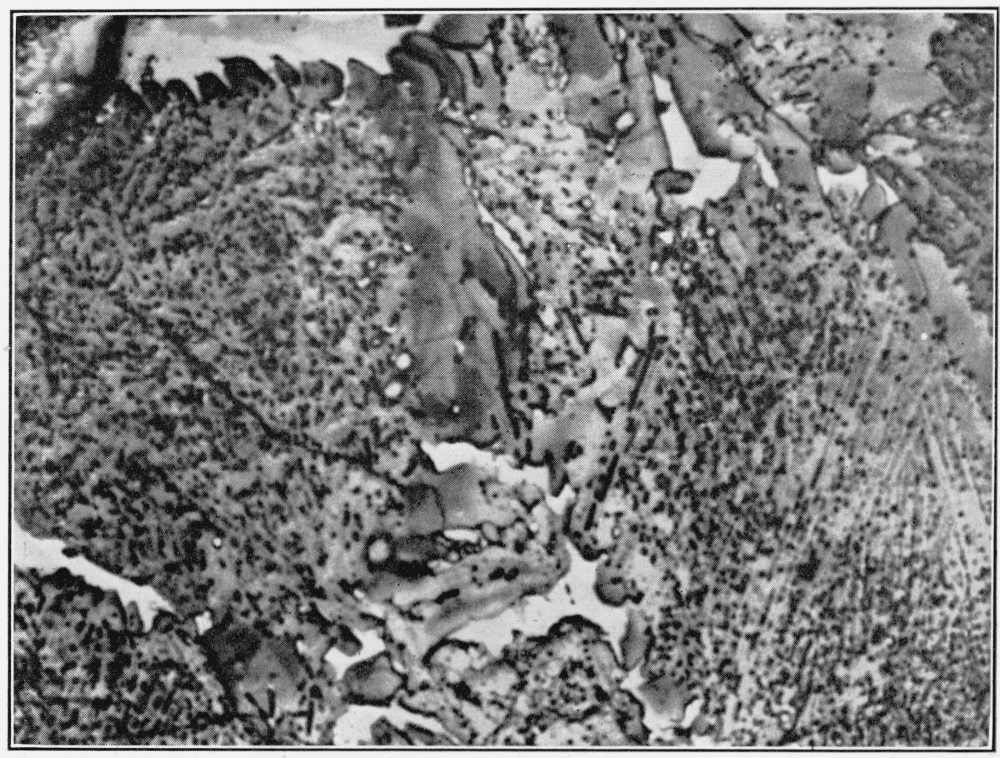

FiguRE 13.-Overgrowths of type III dicalcium silicate on type I in low-heat clinker of brand $\mathrm{B}$.

Reflected light. Magnification 1,000 times.

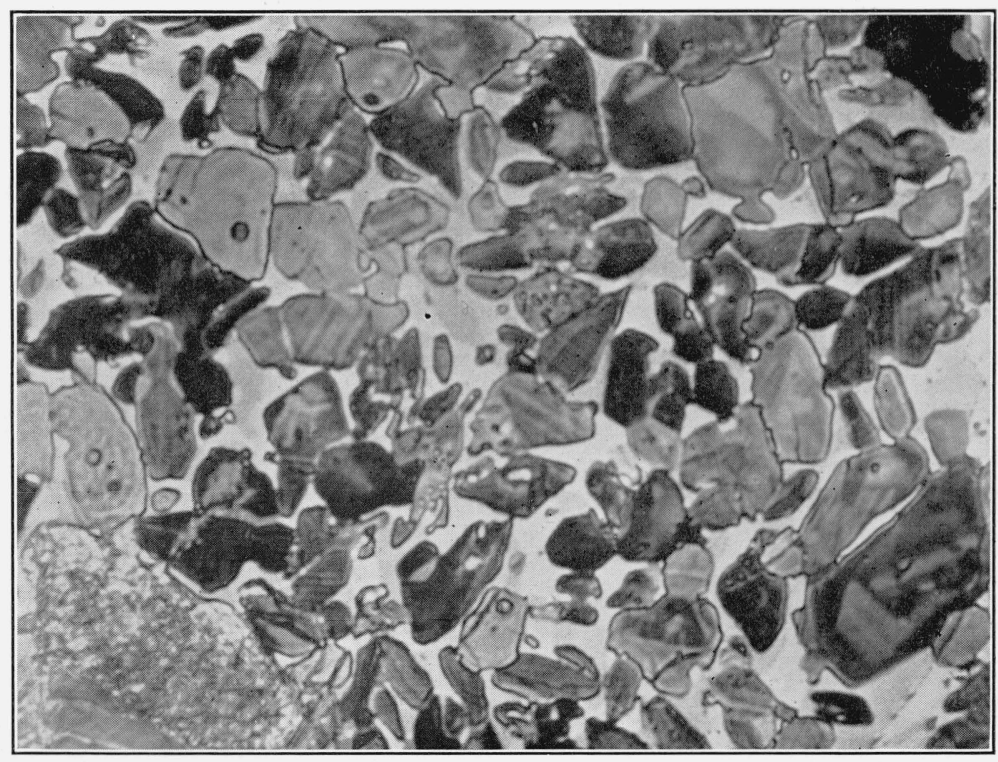

FIGURE 14.-Laboratory prepared low-heat clinker quenched after cooling slowly from 1,375 to $1,275^{\circ} \mathrm{C}$.

Showing $2 \mathrm{CaO} . \mathrm{SiO}_{2}$ of types II and III. Reflected light. Magnification 500 times. 


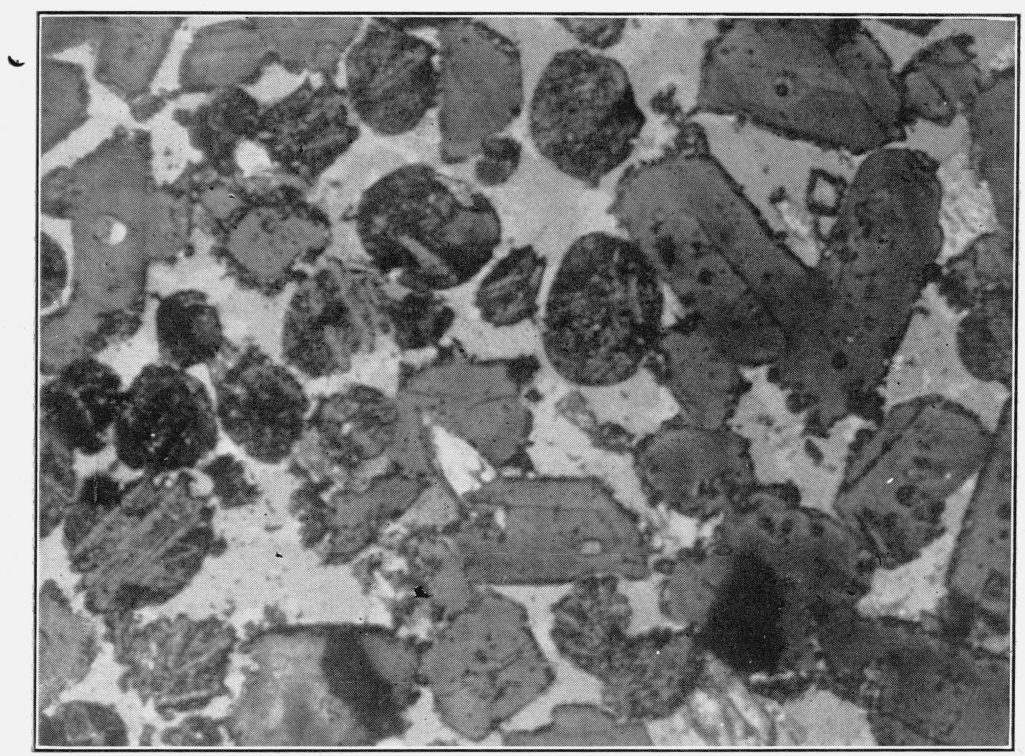

FIGURE 15.-Normal portland cement clinker with $\mathrm{Al}_{2} \mathrm{O}_{3} / \mathrm{Fe}_{2} \mathrm{O}_{3}$ ratio of 2.5. Reflected light. Magnification 500 times. 


\section{CONSTITUENT C}

The third constituent of portland cement clinker has been identified as $4 \mathrm{CaO} \cdot \mathrm{Al}_{2} \mathrm{O}_{3} \cdot \mathrm{Fe}_{2} \mathrm{O}_{3}$ by optical properties and diffraction patterns ${ }^{20}$ It is seen in reflected light as highly reflecting grains associated with the fourth constituent in the matrix surrounding grains of $3 \mathrm{CaO} \cdot \mathrm{SiO}_{2}$ and $2 \mathrm{CaO} \cdot \mathrm{SiO}_{2}$ (fig. 2 and 4). This constituent sometimes occurs as crystals with distinctly prismatic habit but more frequently as aggregates of irregular shape. It is evidently identical with the compound which is observed with transmitted light in thin sections or powder preparations as interstitial grains having high indices of refraction (mean index about 2.03), moderately strong double refraction, weak to strong pleochroism, and frequently prismatic habit. Aggregates of crystals of this compound in cement clinker may be resolved by examination with crossed nicols in reflected light, using an intense illuminant such as an arc lamp, where the difference in extinction position in the individual crystals is exhibited.

$4 \mathrm{CaO} \cdot \mathrm{Al}_{2} \mathrm{O}_{3} \cdot \mathrm{Fe}_{2} \mathrm{O}_{3}$ is known to become decidedly more pleochroic in the presence of $\mathrm{MgO}$ and presumably the $\mathrm{MgO}$ must enter into solid solution. Schwiete and zur Strassen ${ }^{21}$ limit the solid solution of $\mathrm{MgO}$ in $4 \mathrm{CaO} \cdot \mathrm{Al}_{2} \mathrm{O}_{3} \cdot \mathrm{Fe}_{2} \mathrm{O}_{3}$ to 2 percent in the binary system. Their method is based on the relative intensity of lines in the $\mathrm{X}$-ray patterns and appears to be susceptible of large errors. Some preliminary experiments in this laboratory indicate that the maximum solid solubility of $\mathrm{MgO}$ in $4 \mathrm{CaO} \cdot \mathrm{Al}_{2} \mathrm{O}_{3} \cdot \mathrm{Fe}_{2} \mathrm{O}_{3}$ is less than 1 percent. The extent of solution of other clinker compounds in $4 \mathrm{CaO} \cdot \mathrm{Al}_{2} \mathrm{O}_{3} \cdot \mathrm{Fe}_{2} \mathrm{O}_{3}$ is practically unknown. Indirect evidence is that it is small.

\section{CONSTITUENT D}

The composition of the fourth constituent of portland cement clinker has not been determined with certainty. Tricalcium aluminate is present in mixtures of $\mathrm{CaO}, \mathrm{Al}_{2} \mathrm{O}_{3}, \mathrm{Fe}_{2} \mathrm{O}_{3}$, and $\mathrm{SiO}_{2}$ which lie within the range of portland cement compositions and which have been completely crystallized under equilibrium conditions. In commercial clinker, however, the identification by microscopic methods is doubtful. By X-ray patterns this compound has been identified only in clinkers which contain $\mathrm{Al}_{2} \mathrm{O}_{3}$ in greater than normal amounts. ${ }^{22}$

In polished etched specimens observed by reflected light constituent $\mathrm{D}$ is found to occur in the matrix of clinker intimately associated with $4 \mathrm{CaO} \cdot \mathrm{Al}_{2} \mathrm{O}_{3} \cdot \mathrm{Fe}_{2} \mathrm{O}_{3}$ (figs. 1, 2, 4, and 15). It etches less readily than tricalcium silicate or dicalcium silicate and has much lower reflectivity than $4 \mathrm{CaO} \cdot \mathrm{Al}_{2} \mathrm{O}_{3} \cdot \mathrm{Fe}_{2} \mathrm{O}_{3}$. In examining the low-heat clinkers used for cements for Boulder Dam it was found that the constituents were well differentiated, even the in terstitial constituents being readily distinguished with the metallographic microscope.

In most specimens of commercial clinker the interstitial material cannot be resolved microscopically in thin sections, and even in powder preparationsit is of ten difficult to distinguish between $4 \mathrm{CaO} \cdot \mathrm{Al}_{2} \mathrm{O}_{3} \cdot \mathrm{Fe}_{2} \mathrm{O}_{3}$ and the intimately associated constituent $\mathrm{D}$. In powder preparations of the Boulder Dam cement it was found that the constituent closely associated with $4 \mathrm{CaO} \cdot \mathrm{Al}_{2} \mathrm{O}_{3} \cdot \mathrm{Fe}_{2} \mathrm{O}_{3}$ was isotropic, with an index

\footnotetext{
${ }_{20}$ W. C. Hansen, L. T. Brownmiller, and R. H. Bogue, J. Am. Chem. Soc. 50, 396 (1928). L. T. Brown. miller and R. H. Bogue, BS J. Research 5, 813 (1930) RP233.

${ }_{21}$ Zement 23, 511-514 (1934).

${ }_{22}$ L. T. Brownmiller and R. H. Bogue, Am. J. Sci. 20, 241 (1930).
} 
of refraction of about 1.64. The index was too low for $3 \mathrm{CaO} \cdot \mathrm{Al}_{2} \mathrm{O}_{3}$ and did not correspond well to any probable crystalline compound. Therefore, the constituent was presumed to be glass. Since $3 \mathrm{CaO} \cdot \mathrm{Al}_{2} \mathrm{O}_{3}$ is frequently the last compound to crystallize, the difference in composition between it and the glass resulting from more rapid cooling is not great. The ratio of constituent $\mathrm{D}$ to constituent $\mathrm{C}$ is related roughly to the ratio $\mathrm{Al}_{2} \mathrm{O}_{3} / \mathrm{Fe}_{2} \mathrm{O}_{3}$. This is indicated by a comparison of figures 14 and 15 , the clinker represented in figure 14 having an $\mathrm{Al}_{2} \mathrm{O}_{3} / \mathrm{Fe}_{2} \mathrm{O}_{3}$ ratio of 1.0 and that in figure 15 having a ratio of 2.5 .

Further investigations are in progress in an attempt to identify constituent $\mathrm{D}$ in other types of clinker, particularly by developing etching reagents which will give positive distinctions between $3 \mathrm{CaO} \cdot \mathrm{Al}_{2} \mathrm{O}_{3}$ and the glass which may be present.

\section{ACCESSORY CONSTITUENTS}

Free $\mathrm{CaO}$ is frequently present in small amounts in cement clinker either as a result of incomplete combination during clinkering or because of improper batch composition. It occurs typically in rounded isotropic grains and usually as inclusions in A (tricalcium silicate) and in $B$ (dicalcium silicate). Because of its high refractive index (1.83) it is readily distinguished in thin sections. In specimens prepared for metallographic observation free $\mathrm{CaO}$ is etched by dilute nitric acid more readily than other constituents and appears as minute rounded pits.

Since free $\mathrm{MgO}$ occurs as isotropic grains with an index of refraction (1.736) very near that of the other principal clinker constituents it is not as readily identified as is free $\mathrm{CaO}$. In polished and etched specimens free $\mathrm{MgO}$ appears as small grains, sometimes rounded and sometimes with visible octahedral outlines, but always lacking perceptible internal structure. It is noteworthy that in many cement clinker specimens which contain as much as 4 percent of $\mathrm{MgO}$ no crystals of magnesia can be observed even with the most painstaking examination. It is not known whether this amount of $\mathrm{MgO}$ is taken into solid solution by other crystalline compounds or whether it is dissolved in glass present in the clinker. This problem is now being studied.

\section{QUANTITATIVE MEASUREMENTS}

Quantitative measurements of the relative amounts of the various constituents present in cement clinker are of considerable value in understanding the composition of the constituents, because systematic deviations from calculated compound composition may indicate solid solution or incomplete crystallization. The metallographic method, utilizing one of the integrating micrometer stages, ${ }^{23}$ is particularly suitable for quantitative measurements because of elimination of overlap of crystals and the possibility of accurate setting on the crystal boundaries. Preliminary measurements on two types of clinker indicate that the $3 \mathrm{CaO} . \mathrm{SiO}_{2}$ content is higher by microscopic analysis than by calculation from chemical composition and that the amount of constituent $\mathrm{D}$ is less than the calculated amount of $3 \mathrm{CaO}$.$\mathrm{Al}_{2} \mathrm{O}_{3}$. This problem is being studied further by quantitative meas"' ements on clinker specimens which have been analyzed chemically.

${ }^{23}$ C. K. Wentworth, J. Geol. 21, 228-232 (1923). 


\section{SUMMARY}

The metallographic method of microscopic examination using polished and etched specimens, when combined with the usual petrographic methods, aids considerably in determining the composition of the crystalline constituents of portland cement clinker.

The four major constituents of cement clinker are differentiated easily by the metallographic method. The characteristic structures and modes of occurrence of each major constituent are described and illustrated.

The tricalcium silicate crystals in many cement clinkers are not pure $3 \mathrm{CaO} . \mathrm{SiO}_{2}$, but give evidence by three methods of examination that they contain significant quantities of other material in solid solution.

The twinning structures in dicalcium silicate depend in part on the temperature to which they have been heated and the method of cooling. The apparent divergence in optical properties of specimens of $2 \mathrm{CaO} . \mathrm{SiO}_{2}$ heated under different conditions may be due to the presence of twinning bands and not to the actual existence of the $\alpha$ form at room temperature.

In some types of commercial portland cement clinker glass is present and tricalcium aluminate is absent. Evidence as to the existence of $3 \mathrm{CaO} \cdot \mathrm{Al}_{2} \mathrm{O}_{3}$ in normal commercial portland cement clinker is questionable.

Quantitative microscopic measurements of the relative amounts of constituents may be of considerable value in the determination of the nature of the constituents.

Washington, June 22, 1936. 